\title{
Implementation of Human Rights and Rights to Health for People Living with HIV / AIDS in Albania
}

\author{
Urjana Çuri \\ Universiteti Kristal, Fier, Albania \\ urjanac@yahoo.com
}

\section{Doi:10.5901/mjss.2014.v5n4p534}

\section{Abstract}

Without doubt, HIV / AIDS is a global epidemic, and is defined by UNDP as a disease " that caused the change of the single greater human development in modern history. The epidemic of HIV / AIDS is now a global crisis and is part of one of the most difficult challenges for development and social progress. Throughout the years of the fight against AIDS has been clear that human rights are essential for an effective response to HIV. In countries where human rights are not are protected, people suffer more stigma and discrimination, get ill and are are unable to support themselves and their families, and if they do not receive treatment and may die. HIV / AIDS is a major threat to the world of work, particularly in relation to discrimination and stigmatization of workers and people affected by HIV / AIDS. Approach based on human rights states that all people should enjoy a pleasant life in which every person is able to develop his human potential. Human rights set global standards for the welfare and human development. As a derivative approach to human rights approach is developed in the right to health, which means that the norms and principles of human rights are integrated into the design, implementation, monitoring and evaluation of health policies and programs.

Keywords: Hiv/Aids, Human rights and HIV / AIDS, International Covenant on Economic, Social and Cultural Rights, Declaration of Commitment on HIV / AIDS.

\section{Epidemic World of HIV / AIDS}

At the beginning of the epidemic of HIV / AIDS in many countries intervention focused on addressing HIV as a health issue, ignoring the social, economic and human rights that affect the prevention and care.

The approach based on human rights states that all people should enjoy a pleasant life in which every person is able to develop his human potential. Human rights set global standards for the welfare and human development. Based approach to human rights helps in meeting human rights and improve access to information, services and health care treatment (UNAIDS 2000). This approach focuses in particular on ways of empowering individuals and communities, especially marginalized groups, to understand and protect their rights.

As a derivative approach to human rights -based approach is developed in the right to health, which means that the norms and principles of human rights are integrated into the design, implementation, monitoring and evaluation of health policies and programs (Jochnik,1999). These include norms and principles of human dignity, needs and rights of vulnerable groups and the security that health systems are accessible to all (OBSH, 2010). Special attention is paid to the principle of equality and freedom from discrimination. This approach is aimed at fulfilling the right to health and all other human rights related to health. Although many organizations describe as access to health based on the right, there is no definition of what it involves. All these organizations seem concerned at the fact that vulnerable populations have to enlist the services they need, but in practice, they have used different approaches to the inclusion of human rights in different stages of the programming cycle, namely the analysis of the situation, planning, implementation, monitoring and evaluation (UNAIDS, 2005).

Over the last 20 years, the epidemic of HIV / AIDS has been one of the key elements related to clarify health and rights. These issues have attracted the attention of policy makers and law and strengthened the role and limits of responsibility held by the state and other stakeholders on issues related to health and related services (Gruskin \& Tarantola, 2001). The first global strategy on public health, which clearly included the issue of human rights was held in 1980, when Jonathan Mann directed the Global Programme on AIDS WHO. Although this strategy was motivated in part because of the abuse inflicted on people living with HIV, inclusion of human rights was largely due to data showing that discrimination was putting these people out of care and prevention programs (Mann \& Tarantola, 1998). Since 1980, the 
response to the HIV epidemic has focused attention on the rights of vulnerable groups and society and the necessity to prevent discrimination in legal documents and in practice.

The link between human rights and health is well explained in the WHO definition of health does : "Health is a state of complete physical, mental and social and not merely the absence of disease or physical helplessness of the body " and that "the level of high achieving health is one of the fundamental rights of every human being. " This definition introduces an important concept and practical implications illustrates the indivisibility and interdependence of human rights and how they relate to the health. Rights related to discrimination, autonomy, information, education and participation are part of an indivisible whole and the achievement of the highest standard of health, as well as ownership of the right to health is inseparable from the rights of others, as civil, political, economic, social or cultural.

Health, as a universal human right, it means equal opportunity for quality health care regardless of race, gender, social status, economic and geographical position. Mahler, one of the former directors of WHO, said that the central issue of health is the ethical basis of its development. This means that health issues should be considered in a wider social context, including the impact of political and economic forces in public health (Toebes,Kirby 1999).

The application of human rights in relation to health means the use of norms, standards and mechanisms at national and international health care systems and to work for economic development and health policies in the national and international level.

Completion of the right to health is naturally related to the implementation of a range of other rights such as the right of every individual to life, liberty and security of the individual, the right to receive and give information of all kinds, the right to be ' were protected from violence, the right to non-discrimination, the right to be equal in front of low, etc. Governments are responsible for the people to create opportunities for a better health through the respect, protection and fulfillment of rights (such as the inviolable rights, prevention of violations of rights, creation of policies, structures and resources to promote and implement the right ). This responsibility goes beyond measures for essential services related to health and health determinants, such as the provision of an education, food and housing appropriate and suitable working conditions (Martikainen, Stansfeld 1999).

Linking between people and the environment is complex and lack of fulfillment of human rights and their effects on the main determinants of health need for careful research. Human rights include civil, political, economic, social and cultural. They are involved in international law, treaties and declarations by many, starting with the Universal Declaration of Human Rights of the United Nations in 1948 and continue with the Declaration of Commitment on HIV / AIDS, adopted in 2001 at the Special Session HIV / AIDS, UN General Assembly, thus being the first instrument that puts HIV / AIDS on the agenda of national governments. This statement was followed by the 2006 Political Declaration on a high -level meeting of the UN General Assembly on issues of HIV / AIDS. 2006 Political Declaration emphasizes the stigma and discrimination and considers them as a critical element in the fight against this global epidemic disease. Stigma has a variety of effects, such as, for example, delays in testing for HIV, the restriction on the use of preventive programs, impeding the adoption of preventive behaviors and status detection.

International Guidelines on HIV / AIDS and Human Rights was originally adopted in 1996. In 2001, the United Nations Commission on Human Rights adopted a resolution, which stated that the right to the highest attainable standard of health includes access to antiretroviral therapy for HIV / AIDS . Further, in 2006, adopted the unified version of the International Guidelines on HIV / AIDS and Human Rights. The guide contains measures to promote and protect human rights and to achieve public health goals related to International HIV International Guidelines aims to assist States in establishing a positive response to HIV / AIDS, which is effective in reducing the impact HIV / AIDS and in accordance with human rights and fundamental freedoms, however, is the responsibility of States to better fulfill the obligations they have for human rights and to promote public health in the context of the respective political, cultural and religious. The above documents highlight the importance of promoting and protecting human rights as a prerequisite for health and wellbeing. Although attention may focus on specific rights, all rights are interrelated and interdependent, and as a result rare individuals may suffer neglect or violation of a single right. Also, although the right to health creates the legal basis and the main human rights and health, today more and more of an emphasis than morbidity health, health systems rather than health care insurance. Addressing the effects of discrimination, gender issues related to health and service delivery also covered by other rights, again showing how they are related to human rights. International law of human rights, as reflected in the International Guidelines on HIV / AIDS and Human Rights, does not provide or claim to provide a moral code to live with HIV I AIDS. They say nothing, for example, about our own moral responsibilities to care for infected people, although these laws address the obligations of states in these areas. Historically, approaches to human rights in developing countries have tended to privilege the civil and political rights and socio - economic development. In the early years of the epidemic, attention was focused on PJHA and discrimination against vulnerable groups. For many 
developing countries as a narrow concept of rights failed to integrate with a full line of social factors, political and cultural, highlighting the vulnerability to HIV and AIDS response (Heywood \& Altman, 2000).

\section{HIV / AIDS in Albania}

The first case of HIV infected people in Albania in May 1993 was diagnosed through a routine blood (Harxhi, A., Dragoti, M., Todhri, F., Stastoli, A., Zazo, A, 2005). Albania still claims the lowest prevalence of HIV / AIDS, although it has increased in recent years. However the trend of HIV infection is increasing and estimates show a high number of undiagnosed cases. This highlights the fact that it is very important that the epidemiological surveillance system continuously strengthened and promoted VCT centers ( Centres of Voluntary Counselling and Testing ), particularly for vulnerable groups.

By the end of 2013 identified 555 cases infected with HIV ( as cumulative number of cases since the first case in 1993, so all cases over the period 1993-2013), 70 new cases were identified in 2013. Regarding the distribution of HIV cases by gender can say that $70 \%$ ( 390 cases ) of them are male and $30 \%$ ( 165 cases ) were female. The largest number of these cases were infected through sexual contact ( 84 - HETE and $9 \%$ homo - bisexual) age group most affected by the infection is $25-45$ years (Gender Alliance, 2004). Transmission of HIV through infected blood was confirmed in $3 \%$ of cases and transmission from mother to child in $4 \%$ of cases. In terms of geographical distribution of HIV cases, mostly located in the city of Tirana ( $52 \%$ of cases ). A late diagnosis remains a problem in our country, as 50 $\%$ or 35 new cases were diagnosed in 2012 in the stage of the disease (Wagner \& Nunn, 1995). Immigrants have higher levels of HIV infection compared to people who did not move. Medical care and treatment for children with HIV / AIDS is offered only at the Pediatric Service of the University Hospital Center in Tirana, while the children who pass the age of 14 years referred to Infectious Service to follow at the increase in UHC and Outpatient Clinic at this service.

However, specific socio - economic conditions of the country and regional context of HIV / AIDS impact on vulnerability and risk for a rapid spread of the epidemic HIV / AIDS, especially in the most vulnerable groups ( groups with high risk ) population. Young men and young MSM represent Gipsy risky sexual behavior in terms of number of partners, where over $50 \%$ of them have been more than 3-4 sexual partners in the last year (Harxhi Dragoti, 2005). In addition, results from epidemiological surveillance studies of second -generation ( Bio - BSS studies therefore combination also with biological or behavioral surveillance), conducted in 2005 and 2008 show that risky behaviors are still very present in populations most vulnerable, such as men who have sex with men and / or injection drug users.

Due to the ever-changing needs, MH and IPH prepared and drafted a new law on HIV / AIDS in Albania, which was approved by parliament in June 2008. The law treats the most critical legal aspects of HIV / AIDS including discrimination, the right to keep the work, approval for the provision of information, confidentiality, free access to information and treatment, establishing " safe places " where people infected can have access to treatment, and a complaints mechanism. The law provides for the treatment and care as well as new possibilities for scientific research on HIV / AIDS.

Measures taken by Albania on HIV / AIDS have been concentrated in prevention measures include primary, secondary and tertiary. A good part of the preventive measures of HIV / AIDS health education based on the general sense, especially focusing on populations with risky behavior in order to change these behaviors. Of particular importance is the respect and promotion of the rights of persons infected with HIV.

ARV therapy for people with HIV I AIDS began in 2004. Near the Infectious Disease Service at the University Hospital Center " Mother Teresa " of Tirana ( UHC ) was set up in 2007 a Outpatient Center ( actually VCT ) for outpatients. This center provides services in the areas of psycho- social support, counseling and voluntary testing for HIV I STI preventive medical services, and especially with ARV treatment.

According to a study conducted in 2008, $53 \%$ of people living with HIV / AIDS in Albania doi not benefit from welfare schemes, as do not want to reveal their HIV status. About $68 \%$ of cases report that attitudes have changed others when they learned about HIV status. The need for psychological support is quite large : $78 \%$ of reported cases that need to talk to a psychologist. The high level of stigma and prejudice often compels people living with HIV to give up the services and develop protective mechanisms and barriers that are not permeable to others. This is their avoidance of consumption in all dimensions, developing a new mechanism to control which must guarantee secrecy.

\section{The Definition of Social Support and HIV / AIDS}

Social support is particularly relevant due to HIV that offers opportunities to address issues such as gender inequality, 
stigma and discrimination, which exacerbate vulnerability and increase inequalities faced by populations that have a high risk of infection. Social support forPJHA is directly related to quality of life and health. Removal, rejection and isolation could threaten the PJHA hope and prosperity. Supportive social environments, especially family and friends, directly affect the quality of life increased the PJHA (Ferrans C \& Lashley F 2001).

Russel and Schneider (2000) define formal support as a support offered by government institutions, private clinics, NGOs and voluntary organizations. Informal support is support provided by family, friends and the community at large. Garbarino (1983) points out that many people seek the support of friends, family and relatives before they seek professional support from doctors or counselors.

\section{Human Rights and HIV / AIDS : International Standards}

Over two decades of treating HIV epidemic is confirmed that the protection and promotion of human rights constitute an important component in preventing transmission of HIV and reduce the impact of HIV / AIDS. Declaration of Commitment on HIV / AIDS and the 2001 Political Declaration on HIV / AIDS of 2006 highlight the importance of human rights and a national response to HIV based on the approach of human rights and fundamental freedoms.

Although there is no treaty or international agreement that specifically addresses HIV, has a number of provisions of international treaties and declarations of human rights that are interpreted to have a number of implications to effectively respond to AIDS. These include :

The right to the highest standard of health. International Pact of the Economic, Social and Cultural Rights ( Article 12 ) recognizes the right of everyone to the enjoyment of the highest standards of physical and mental health. As part of this commitment, States should take steps to prevent, treat and control epidemic diseases. According to general comment no. 14 (2000) on the rights and the highest standards achievable health, prevention, treatment and control of epidemic, epidemics and other diseases require the establishment of prevention and education programs for health issues related to behavior such as infections sexually transmitted diseases, especially HIV / AIDS, adversely affecting sexual and reproductive health. These programs should promote social determinants of good health, such as a safe environment, education, economic development and gender equality.

The right to health includes four elements relate to each other (CESCR, 2000): availability ( state must provide functional public services and health care facilities ), accessibility ( health services and facilities should be made available to all without discrimination ) ; acceptability ( health facilities and services must respect medical ethics and should be culturally appropriate, quality ( health services and facilities should be adequate as it by scientific and medical and based on high standards of quality ).

Non-discrimination and equality before the law. International Convention on Human Rights guarantees the right to equal protection before the law and freedom from discrimination of various forms. Commission on Human Rights (1996) confirmed that " other status " in non-discrimination provisions in international treaties of human rights should be interpreted including health status, including HIV / AIDS.

The rights of children. Under the Convention on the Rights of the Child and the Optional Protocols, children enjoy many of the same rights as adults, cited here without those rights that are specific to children. Children have the right to freedom from trafficking, prostitution, sexual exploitation and abuse, the right to seek and receive information on HIV, and the right to special protection and assistance if deprived of a family environment. They also enjoy the right to education, health, the right to inherit property. The right to special protection and assistance if deprived of a family environment, protects children if they are orphaned due to AIDS.

The right to marry and to found a family. Article 23 of the International Covenant on Civil and Political Rights recognizes the rights of men and women to marry and to found a family. Mandatory premarital testing as a prerequisite for marriage, or forced sterilization or abortion of women living with HIV would violate those rights and other human rights.

The right to education. That 's right, laid down in Article 26 of the Universal Declaration of Human Rights and article 13 of the International Covenant on Economic, Social and Cultural Rights, guarantees that those living with HIV are not denied education because of their HIV status positive. The right to education also includes the obligation of States to promote understanding, respect, tolerance and non - discrimination of people living with HIV. Moreover , it rightly emphasizes that individuals have the right to receive information about HIV(Commission on Human Rights, 2003).

The right to freedom of expression and information. Article 19 of the International Covenant on Civil and Political Rights, states the right to seek information about treatment, care, support and prevention of HIV. States are required toprovide appropriate information permanent and effective methods for preventing the transmission of HIV and 
to develop and distribute information easily accessible to all persons.

Freedom of assembly and association. The right of peaceful assembly and association, as provided in Article 20 of the Universal Declaration of Human Rights and article 22 of the International Covenant on Civil and Political Rights, are often denied civil society organizations working on issues of human rights and HIV.

Declaration of Commitment on HIV / AIDS and the Political Declaration on HIV I AIDS stress the need for active participation of people living with HIV, vulnerable groups and underlines the importance of civil society to respond to the epidemic and to increase coverage of needs in relation to prevention, treatment, care and support services for HIV.

The right to work. That 's right, laid down in Article 23 of the Universal Declaration of Human Rights and articles 6 and 7 of the International Covenant on Economic, Social and Cultural Rights, including the right of every person to be employed without any conditions except conditions professional needed. This right is violated when an employer requires mandatory HIV testing of employees or employee ceases or refuses because HIV positive. The right to work further guarantees the right to safe working conditions and healthy. Even when there is a possibility of transmission of HIV, for example, in the health sector, states should take measures to minimize these risks, as, for example, through training and implementation of " universal procedures " against all infections, including HIV.

\section{The right to enjoy the benefits of scientific progress and its applications.}

This right, which is defined in Article 15 of the International Covenant on Economic, Social and Cultural Rights, is important in relation to HIV in view of the advances that have been made in connection with the diagnosis and treatment, as well as the development of vaccines and other prevention tools.

\section{The right of freedom to move.}

That 's right, as provided in Article 12 of the International Covenant on Civil and Political Rights and Article 13 of the Universal Declaration of Human Rights includes the right of every person to freely choose his place of her residence, and the rights of citizens to enter and leave their country. As long as there is no public health rationale for restricting liberty of movement or choice of place of residence for people living with HIV, such restrictions will were discriminatory.

\section{The right to an adequate standard of living and social security.}

The enjoyment of this right provided for in Article 25 of the Universal Declaration of Human Rights and articles 9 and 11 of the International Covenant on Economic, Social and Cultural. This right is essential for reducing the impact that AIDS has on the lives of people living with HIV and their families. States should ensure that persons living with HIV are not discriminated against and denied not an adequate standard of living and social security. Political Declaration on HIV I AIDS in 2006 highlights the importance of ensuring access to social and health services, the importance of care and support for people living with HIV and members of vulnerable groups. States must commit to addressing the needs of children orphaned and infected by AIDS, building and supporting social security systems that protect them.

The right to participate in political and cultural life.

This right, which is based on Article 25 of the International Covenant on Civil and Political Rights and Article 15 of the International Covenant on Economic, Social and Cultural Rights, it is essential to ensure the participation of those affected by HIV in the development, implementation and evaluation of policies and programs related to HIV.

\section{The right to seek and enjoy asylum.}

Everyone has the right to seek and to enjoy protection from persecution in other countries. According to the 1951 Convention relating to the Status of Refugees and legal right under international countries, in accordance with the principle of non - refoulement, can not return a refugee to a country where he or she faces persecution or torture. Thus, states can not return a refugee to persecution on the basis of the status of his / her HIV status. Moreover, they can take specific measures, such as mandatory testing for HIV, to exclude HIV - positive individuals by examination or provision of asylum.

\section{Human Rights and HIV / AIDS}

In many countries HIV / AIDS is viewed and treated as a health issue, ignoring the rights of social, economic and human impact on both prevention and treatment.

HIV / AIDS acts as a spotlight, exposing inequalities, including gender inequality, globally. HIV / AIDS epidemics are most pronounced in regions where poverty and economic inequality are obvious and acute, where gender inequality is pervasive and access to public services is weak or almost non-existent.

HIV / AIDS has opened debates about issues related to sexuality and has served to highlight the importance of gender equality in sexual relationships as well as the importance of equality and respect in all social relations.

In a statement to the Extraordinary Session of the General Assembly of the United Nations on HIV I AIDS in 2001, 
Stephanie Urdang, Advisor Development Fund for Women United Nations, pointed to a growing global awareness of the fact that the epidemic has less to do with epidemiology and much more with social factors.

In early HIV / AIDS in many countries seen and treated as a health issue, ignoring the rights of social, economic and human. But HIV / AIDS is an issue of human rights, because : ( i) lack of access to prevention methods, and materials appropriate information, treatment and medical care, leading to vulnerability to HIV related rights violations human, such as poverty, inequality, racism and sexism. ( ii ) People living with HIV / AIDS and those affected by outbreaks often are unable to live a life of equality, dignity and freedom as to their rights are often violated based on their status as HIV status (AGJZH, 2004).

This includes the right to privacy, confidentiality, access to appropriate medical services, services of sexual and reproductive health, employment, education, freedom of movement and the right to travel.

\section{Protection through International Instruments and National Human Rights}

The United Nations has a number of legal instruments for the protection of human rights instruments that can be used to protect the rights and freedoms of individuals living with HIV / AIDS. Instruments of human rights established under international law to protect all persons without distinction of any kind such as race, color, sex, language, religion, political and other opinion, national or social origin, property status, the birth or other status, considered to protect the rights and freedoms of all individuals living with HIV / AIDS. Some of these instruments are created from conventions or treaties are binding on states that have ratified them. There are also statements or international standards of human rights, which are not legally binding on states, but considered authoritative interpretations of international requirements under the convention. It is important to note that these standards are enshrined in international law and represent a consensus of international opinion. In most cases, they are compiled and issued by the General Assembly of the UN, the Council of Human Rights and the High Commissioner's Office, or can be developed through the work of other specialized agencies of UN . They can be used to guide the development or review of policies, plans or programs, the adoption of relevant legislation, and the restructuring of health services in order to ensure a more effective response to those living with HIV I AIDS.

\subsection{International Covenant on Economic, Social and Cultural Rights ( 1966) .}

Article 12 of the Convention recognizes the universal right " to enjoy the highest standard possible physical and mental health " and requires signatories to take steps to prevent, treat and control the disease and to create the necessary conditions " to which provide all medical service and medical attention in case of illness. " Article 6 recognizes the universal right to work, while Article 13 states that education should be provided to all individuals equally. These two conventions, along with the Universal Declaration of Human Rights, constitute what is known as the International Bill of Rights. All three documents provide protection against discrimination of people living with HIV / AIDS and their families.

\subsection{General Comment no. 3 , the Convention on the Rights of the Child V / AIDS and the Rights of the, "HI Child " (2003).}

Having noted that the global epidemic HIV / AIDS has " drastically changed the world in which children live," adds the Comment Entry in most of the world, most new infections belong to young people aged 15 - 25 years or younger. Although the issue of children with HIV / AIDS is perceived mainly as a medical or health problem, the impact of present illness ' affects all their rights - civil, political, economic, social, and cultural. " Therefore, even though the health rights ( Article 24 of the Convention ) is of great importance, comment cites other important articles, which, according to him, should serve as " guiding themes for the review of HIV / AIDS at all levels of prevention, treatment, care and support. These are : Article 2 (right to non discrimination);

Article 3 (rights of the child to take account of the interests of his / her highest rank view), and Article 12 ( the right to respect views his / her ).

\subsection{International Guidelines on HIV / AIDS and Human Rights (1997, 2006).}

These guidelines provide direction for the policies of governments, international organizations, NGOs, civil society groups and others to develop and implement national strategies that adequately address issues raised by HIV / AIDS. From the 
12 guidelines, it no. 6 has attracted more attention. " States should enact legislation to provide for the regulation of goods, services and information related to HIV " The prevention, treatment, care and support are equally amplifier element and serve as an extension for responding effectively to HIV / AIDS.

Based on the principles of human rights, universal access requires that these goods, services, and information not only be available, acceptable and of good quality, but also within physical and affordable for everyone.

States are encouraged to include community participation in all phases of design and ensure that punitive penal codes and systems comply with international obligations to human rights and not misused to harm those living with HIV I AIDS that supporting legal systems apply to educate people living with HIV / AIDS on their rights and to provide free legal services to enforce those rights, and how the public sector and the private sector develop codes of conduct regarding matters HIV I AIDS to translate the principles of human rights in codes of professional responsibility and practice.

\subsection{Protecting Human Rights in the Context of HIV and AIDS (2005).}

Resolution of the United Nations Commission on Human Rights at its meeting of 61 . Asked state governments to ensure that laws, policies and practices, including those related to the workplace, to respect human rights within the context of HIV / AIDS and to prohibit discrimination because of HIV / AIDS, including through testing and voluntary counseling, education, media and awareness campaigns, improvement and ensuring equal access to the benefits of high quality materials, health care and effective treatment of safe, nurturing and assistance to those who live or are infected with HIV I AIDS about their rights and to assist them in the realization of these rights. States are required to establish, support and strengthen national institutions for human rights and other professional bodies to monitor and enforce human rights in respect of HIV, to eliminate stigma and discrimination associated with HIV and ensure that codes of conduct to respect human rights and dignity in the context of HIV / AIDS, so that people who display their HIV status, they thought that living with HIV and others who are affected should be protected from violence, stigma and discrimination. Moreover, states are required to take appropriate measures to protect the human rights of women and children within the context of HIV I AIDS, in particular, to address gender inequality and violence against women and girls as well as legal and social needs children orphaned or vulnerable by HIV / AIDS and their caregivers needs.

\section{The National Legal Framework}

The Albanian legislation special attention was paid to the guaranteeing of human rights and fundamental freedoms, as one of the pillars of modern civilized society. Human rights today recognize a wider dimension universal and effective respect not only through their declaration of fundamental national acts but also through their institutionalization at the international level.

Legal provisions laid down in international instruments apply directly through the application of legal norms laid down in international instruments or through commitments to adopt these standards as part of domestic law.

Albanian legislation includes a number of laws and regulations, national strategy, accession and ratification conventions that regulate the field of human rights, health, social services, fight against the spread of infectious diseases (HIV / AIDS).

\subsection{Law on Prevention and Control of HIV / AIDS}

Law no. 9952, dated 14.07.2008 " On prevention and control of HIV I AIDS " provides rules for the prevention and control measures for HIV I AIDS care, treatment and support for people living with HIV / AIDS, without any type of discrimination. This law considers to act to stop the stigmatization and discrimination of a person living with HIV I AIDS.

The Ministry of Health is the main institution responsible for the prevention and control of HIV I AIDS. The Ministry of Health coordinates with other ministries and institutions responsible for prevention and control of HIV / AIDS.

The law provides for the duties of local government units, which must include in their services and measures for prevention and control of HIV / AIDS.

The law introduces a number of rights and obligations that people living with HIV / AIDS . Persons living with HIV I AIDS have the right as the right to:

health care, medical drugs, outpatient or inpatient health care free public education at all levels of the educational system, public or private; employment, in accordance with the requirements of the job ; confidentiality of infecting them with HIV / AIDS, refusal of medical examination and treatment, when they are taking full treatment for AIDS, integration 
into the community and society, and to other rights provided by this law and other laws in force.

Persons living with HIV I AIDS have some obligation to implement measures for the prevention and transmission of HIV to others, information on HIV test results positive husband / wife or partner / coexistence, other obligations, the by this law and other laws in force.

The law also banned a series dealing with discrimination of people living with HIV I AIDS , no obligation to perform the test, with the exception of the cases mentioned in the law, confidentiality, etc.

\subsection{Criminal Code of the Republic of Albania}

Law no . 7895, dated 27.1.1995 "Criminal Code of the Republic of Albania " has a duty to protect the independence of the state and its territorial integrity, human dignity, rights and freedoms, constitutional order, property, environment, coexistence and understanding Albanian national minorities and religious coexistence of offenses and their prevention.

In Article 96 of the Criminal Code provides measures of punishment in cases of careless treatment of patients by a doctor or other medical personnel, and failure of therapy or doctor's orders by medical personnel or pharmacist when causing damage serious health endangered the life of the person or has caused his death, when causing infection of patients with HIV / AIDS, punishable by three to seven years.

\subsection{Service law and control of blood transfusion, its products and transplants}

Law no . 8032, dated 16.11.1995 " Law transfusion service and the control of blood products and transplants it " intends to provide security for all manipulations associated with blood, its products and transplants. Under this law, the blood that comes out positive examinations should not be used for transfusion or blood products fabrication. A person who commits receiving blood must immediately inform the donor about the examination results. Informing donors resulting seropositive for HIV / AIDS made by persons appointed for this purpose.

\subsection{The Council of Ministers no. 113, dated 17.02.2011}

"To prevent the transmission of HIV / AIDS and care, counseling and treatment of people living with HIV / AIDS in institutions of education, rehabilitation, medical treatment, residential social care institutions, prisons and places of detention. " This decision provides : providing equally prevention programs and care for persons living with HIV / AIDS, those persons uninfected, confidentiality, non-discrimination non-stigmatisation of persons live with the status of HIV I AIDS, non-refoulement of persons living with HIV I AIDS from the network of educational institutions, medical treatment, residential social care institutions, because of their status, HIV / AIDS, persons with status HIV I AIDS are treated in a fair, appropriate and humane.

The national strategy for gender equality and reduce gender -based violencedomestic violence 2011-2015 provides monitoring and analyzing the impact that has had legislation against discrimination and gender equality, disagreements are identified and treated them to ensure that the implementation of this legislation lead to effective elimination of discrimination against women, especially women belonging to disadvantaged groups ( women and ethnic and linguistic minorities, women with disabilities, elderly women, women living in rural or remote areas, migrant women, women living with HIV / AIDS and women who are discriminated against on the basis of their sexual orientation and gender identity ). Improving sex education teenage boys and girls, to prevent unwanted pregnancies early control to prevent sexually transmitted infections, including HIV / AIDS .and women who are discriminated against on the basis of their sexual orientation and gender identity ). Improving sex education teenage boys and girls, to prevent unwanted pregnancies early control to prevent sexually transmitted infections, including HIV / AIDS.

The national strategy for prevention and control of HIV / AIDS in Albania in the years 2004-2010 the emphasis on measures to be taken to the state in the story to keep Albania a low prevalence of HIV / AIDS. The strategy provides a range of preventive measures and treatment measures for raising the most vulnerable groups.

\section{Conclusions}

- PJHA have difficulty and feel embarrassed to talk about their illness and their lives even though many of them have years of living with this disease. Most do not mention the name of the disease any time. This is an indication that the negative experiences associated with the affected person throughout his life, return barrier 
to seeking and finding the right help.

- Non-disclosure of status anxiety and turn the major obstacle to the lives of these people because you have to find different excuses before family or friends for frequent visits to the hospital, taking medication, etc. Keeping a secret disease is very consuming, has a high social cost, requires the individual to use their limited resources lie and reducing access to social support from circles close. Disclosure of status increases the need for psychosocial support. In other cases, the need to hide your status at any cost, can also be a barrier to getting treatment. There are also cases PJHA to immediately share information on the disease with accompanying persons at the time of testing. The reason relates to the detection of status they need help, especially in the first moments when you just learned about the disease.

- In some cases PJHA choose not to communicate to their parents' illness judged because of health problems and age they will be hard to understand.

- Family, but also choose some ways PJHA self defense, for fear that not infect other family members. They are afraid to embrace their children, despite having information about modes of transmission of the disease.

- PJHA said they felt stigmatized in couple relationships: in all reported cases, men have felt rejected, since only they are infected, while their partner seronegative results. Despite their efforts to protect marriage mates, the fact that they are infected do to be more withdrawn and more protective of their health and other family members.

- Much of PJHA feel stigmatized and not comfortable with the media convey messages about the disease of HIV / AIDS. The way the information provided by the media increase the level of fear among people who are not infected and no awareness of the community about the AIDS disease. Even service providers supporting the same idea that the media is not professional but very superficial convey messages about the disease of HIV / AIDS . missing Truth awareness activities on issues of HIV / AIDS and the various phenomena psycho social, economic, occurring as a result of this disease.

- AIDS related stigma is not lacking in family environment. Stigmatization within the family is perceived as very serious when he repeated continuously and creates tensions and problems in relationships with family members. This creates another obstacle to the creation of social ties and emotional support within the family.

\section{References}

Aggleton, P. Parker R., 2002. A conceptual framework and basis for action: HIVI AIDS stigma and discrimination. UNAIDS.

Gender Alliance for Development, 2004. Gender and HIV / AIDS, report summary, Tirana, Albania. Pg. 18-19.

Alonzo, A. A, \& Reynolds, N. R., 1995. Stigma, HIV and AIDS: An exploration and elaboration of a stigma trajectory. Social Science and Medicine, 41(3), 303-315.

Ansell, N. van Blerk, L., 2005. Joining the conspiracy? Negotiating ethics and emotions in researching (around) AIDS in southern Africa, Ethics, Place and Environment, 8(1), pp 61-81

Antoni, M. H., Baggett, L., Ironson, G., LaPerriere, A., August, S., Klimas, N. 1991. Cognitive-behavioral stress management intervention buffers distress responses and immunologic changes following notification of HIV-1

seropositivity. Journal of Consulting \& Clinical Psychology, 59(6), 906-915.

Antoni, M., 2002. HIV and AIDS. In A. J. Christensen \& M. H. Antoni (Eds.), Chronic Physical Disorders (pp. 191-219). Malden, MA: Blackwell.

Appleton J.V., 1995. Analysing qualitative interview data: addressing issues of validity and reliability. Journal of Advanced Nursing. 22, 5, 993-997

Atkinson J.M., Heritage J., 1984. Structures of Social Action: Studies in Conversation Analysis Cambridge University Press, Cambridge.

Balint J., 2006. Should confidentiality in medicine be absolute? Am J Bioeth 2006, 6:19-20.

Barroso, J., \& Powell-Cope, G. M., 2000. Metasynthesis of quali-tative research on living with HIV infection. Qualitative Health Research, 10, 340-353. doi:10.1177/104973200129118480

Beauchamp, T. Childress, J., 1985. Parimles of Biomedical Ethics. New York : Oxford University Press

Bell, L., 1998. Public and private meetings in diaries: researching family and childcare.

Bennett, O., 1990. Panos Dossier: Triple Jeopardy: Women and AIDS, London: Panos Institute

Berger, B. E., Ferrans, C., \& Lashley, F., 2001. Measuring stigma in people with HIV: Psychometric assessment of the HIV stigma scale. Research in Nursing and Health, 24, 518-529.

Benetar S., 2000. The biotechnology era: a story of two lives. In: Bhatia GS, O'Neill JS, Gall GL, Bendin PD eds. Peace, justice and freedom: human rights challenges for the new millennium. Edmonton: University of Alberta Press, 2000: 245-57.

Berry, D.E., 1993. The emerging epidemiology of rural AIDS. Journal of Rural Health 9 (4), 293-304.

Brunswick, A.F., \& Flory, M.J., 1998. Changing HIV infection rates and risk in an African-American community cohort. AIDS Care 10 (3), 267-281. 